\title{
FACE/UFMG, BDMG e Cedeplar: instituições do planejamento e desenvolvimento de Minas Gerais
}

FACE/UFMG, BDMG and Cedeplar: institutions of planning and development of Minas Gerais

João Antonio de Paula

Universidade Federal de Minas Gerais

\begin{abstract}
The paper presents an overview of the origins and role of BDMG and Cedeplar/UFMG as institutions dedicated to the study of regional planning and development, emphasizing how UFMG's School of Economics provided a bonding space for them.
\end{abstract}

\section{Keywords}

BDMG; Cedeplar; FACE/UFMG; planning; development.

JEL Codes B25; 020.

\section{Resumo}

$O$ artigo apresenta um panorama sobre as origens e o lugar do BDMG e do Cedeplar/UFMG como instituições dedicadas ao estudo do planejamento e desenvolvimento regionais, enfatizando o papel da Faculdade de Ciências Econômicas da UFMG como um espaço de ligação entre ambas.

\section{Palavras-chave}

$B D M G$; Cedeplar; FACE/UFMG; planejamento; desenvolvimento.

Códigos JEL B25; 020. 


\section{Estado e o planejamento econômico em Minas Gerais}

Entre as singularidades tipificadoras da história de Minas Gerais, uma é particularmente expressiva: trata-se da precoce presença ali da máquina estatal, desde os tempos da capitania, e a centralidade que este fato teve sobre o conjunto da vida mineira, seja durante o Império, seja na República. Com efeito, esta longa convivência com o aparato governamental permitiu aos mineiros exercer papel de destaque na consolidação do Estado Nacional Brasileiro seja em perspectiva conservadora, como se deu no caso de Bernardo Pereira de Vasconcelos, do Marquês do Paraná, seja uma perspectiva modernizante, antecipadora do desenvolvimento como se vê com Teófilo Otoni, com João Pinheiro.

fato é que Minas Gerais descobriu cedo a importância do Estado, das políticas públicas e do planejamento como instrumentos decisivos para a realização do desenvolvimento econômico social.

A Revolução de 1930 abriu no Brasil longo período, que se prolongou até 1980, marcado pelo que foi chamado de desenvolvimentismo. Essas tendências, em Minas Gerais, tiveram como instrumento coordenador a Secretaria da Agricultura do Estado, a qual, a partir de 1933, desenvolveu uma série de importantes inciativas seja no campo do planejamento, seja na definição de políticas, seja na montagem de arranjos institucionais inovadores. Mesmo depois de derrubada a ditadura Vargas, em Minas Gerais, no âmbito de governo tido por liberal, teve continuidade a valorização do papel do Estado e do planejamento, de que é exemplar o Plano de Fomento da Produção e Recuperação Econômica, de 1947, primeira tentativa de planejamento econômico sistêmico na esfera estadual no Brasil.

A esse respeito, vale a pena lembrar que deve ser considerada uma efetiva mudança de patamar, na história do planejamento em Minas Gerais, a criação do BDMG. Entre 1962 e 1970, momento crucial da vida contemporânea brasileira, quando estiveram em disputa decisivos projetos sobre o sentido e os compromissos do processo de desenvolvimento econômico e social mineiro e brasileiro, o BDMG ocupou lugar importante, pela pertinência e relevância do que prospectou, avaliou, estudou, induziu e financiou.

Antes do BDMG, e mesmo depois, intentou-se organizar, em Minas Gerais, um sistema de planejamento. A primeira iniciativa nesse sentido é de 1951, com a criação do Conselho Estadual de Economia e Adminis- 
tração, que só foi instalado em 1959. Em 1961, foi criada a Coordenação Geral dos Assuntos do Desenvolvimento Econômico de Minas Gerais, que acabou por ter existência fugaz. No mesmo ano, 1961, foi criado o Conselho do Desenvolvimento do Estado de Minas Gerais - Codemig, que também não prosperou. Em 1965, foi criada a Secretaria de Estado do Desenvolvimento Econômico, que, em 1966, elaborou proposta de constituição de um sistema estadual de planejamento, constituído pelo Conselho Estadual de Planejamento, encarregado de definir as diretrizes básicas da política de planejamento do estado, enquanto um Gabinete de Planejamento, Coordenação e Controle cuidaria dos aspectos técnicos do planejamento (Medeiros, 1966).

Tais esforços eram alimentados pela existência, em Belo Horizonte, da Faculdade de Ciências Econômicas da UFMG, que se constituiu, entre os anos 1950 e 1960, num efetivo centro de ensino e pesquisa em ciências sociais aplicadas, que oferecia cursos de ciências econômicas, ciências contábeis, ciências atuariais, administração pública, sociologia e política e administração de empresas. Entre os professores e alunos desta instituição, estão nomes importantes das ciências sociais brasileiras. Destaquem-se aqui, nomes que tiveram efetiva incidência na construção de uma cultura de planejamento econômico e social em Minas Gerais, como Domício Figueiredo Murta, Lucas Lopes, José de Magalhães Pinto, Paulo Camillo de Oliveira Penna, Júlio Babosa, Fernando Antônio Roquette Reis, Álvaro Fortes Santiago, Élcio Costa Couto, Marneu Ferreira Starling, Paulo Roberto Hadad, Simão Pedro Casasanta, Carlos Maurício Carvalho Ferreira, Antônio Octávio Cintra, Luiz Aureliano Gama de Andrade, Gilmar Benedito Costa, Clélio Campolina Diniz, Paulo de Almeida Paiva, entre outros muitos nomes.

Na verdade o papel da Face/UFMG no planejamento econômico de Minas Gerais e do Brasil é decorrência da competência técnica instalada na Faculdade, do domínio da bibliografia pertinente sobre o tema, e da interação com instituições como o ISEB, o BNDE, a Cepal, o ILPES, que protagonizaram no Brasil o debate sobre o desenvolvimento, sobre o planejamento e sobre o papel do Estado na superação do subdesenvolvimento.

Por mais de uma vez, em mais de um sentido, o BDMG foi chamado a exercer papel importante no processo de desenvolvimento de Minas Gerais. Sua capacidade operacional e de elaboração teórica é um dos grandes ativos do aparato estatal de Minas Gerais. Em 1968, Fernando Reis desta- 
cou, com justo orgulho, o que o Banco tinha conquistado: "o BDMG logrou formar em sua equipe algo equivalente a uma escola de pensamento, cujo maior mérito é, sem dúvida, o de haver defrontado mitos e derrubado pseudotruísmos acerca da problemática econômica e social do Estado" (REIS, 1968).

Foi assim foi com o Diagnóstico da economia mineira, de 1969, com a segunda rodada de estudos abrangentes sobre Minas Gerais conduzida pelo Banco e que se chamou Economia mineira. 1989: diagnóstico e perspectiva, e com a terceira versão da iniciativa, publicada em 2002 - Minas Gerais do Século XXI.

Com efeito, o papel do BDMG no processo de planejamento do desenvolvimento econômico e social de Minas Gerais não se limitou a financiar projetos e programas. Tão importante quanto sua ação como validador de projetos, foi a atuação do Banco como centro de pensamento, como fonte indutora de instituições, como formulador de políticas gerais, de paradigmas interpretativos e operacionais. Celso Furtado disse que o debate econômico, travado nos anos 1950, teve decisivo papel nas transformações que o Brasil vai experimentar a partir daí (Furtado, 1979). Esse debate, bem ou mal, foi protagonizado pela dimensão econômica e por instituições, publicações, que encarnavam, cada qual à sua maneira, a obsedante questão posta para a sociedade brasileira: o desenvolvimento.

A justa compreensão do lugar e do papel do BDMG implica reconhecer a existência de certa tradição cultural, típica de Minas Gerais, que muito precocemente reconheceu a importância do Estado nos processos de desenvolvimento econômico e social, tradição cultural que transbordou limites partidários. Se houve consenso com relação à presença do Estado, no efetivamente substantivo, sobre os legítimos efeitos destinatários do desenvolvimento econômico e social, sobre esse ponto, é claro, não houve e não há consenso, e isso é perfeitamente detectável nas posições sobre o tema de ontem e de hoje. De qualquer modo, atravessado pelas mesmas contradições e impasses que marcaram o debate nacional, a questão do desenvolvimento foi vivida em Minas Gerais tendo o BDMG como sujeito importante. Instituição subordinada ao governo estadual, e às regras federais concernentes a bancos de desenvolvimento, o BDMG refletiu, em sua história, as vicissitudes da vida política de Minas Gerais e do Brasil, sem que se deva exagerar o caráter puramente passivo e reflexo do Banco, já que sempre remanesceu possibilidade de alguma autonomia. Assim, ape- 
sar do golpe de 1964 e da inflexão conservadora da política econômica que a ditadura militar impôs, o BDMG manteve em sua política geral proximidade com as grandes linhas do pensamento desenvolvimentista, como se pode ver no emblemático Diagnóstico da Economia Mineira.

\section{BDMG e UFMG: instituições do planejamento e de- senvolvimento econômico}

Com efeito, é preciso pensar a relação entre a Face/UFMG e o BDMG como simbiótica, na medida em que a atuação do Banco, como instrumento de planejamento do desenvolvimento econômico, em muito se deve à Faculdade, aos seus cursos e discussões sobre economia regional e planejamento econômico, como se vê no artigo de Fernando Reis, publicado na Revista Brasileira de Ciências Sociais, editada pelo professor Júlio Barbosa (Reis, 1963).

No mesmo sentido vai a criação do Cedeplar, em 1967, por meio da iniciativa de economistas do BDMG, Fernando Reis, Álvaro Santiago, Élcio Costa Couto, que eram também professores da Face, e professores em tempo integral da Faculdade - Paulo Roberto Haddad, Carlos Maurício Carvalho Ferreira e José Alberto Magno de Carvalho.

O Centro de Desenvolvimento e Planejamento Regional, Cedeplar, órgão de ensino de pós-graduação e pesquisa, ligado à Face/UFMGtorna-se referência regional, nacional e internacional em estudos e pesquisas sobre planejamento e desenvolvimento regional.

Não há na afirmação da importância do BDMG, como sujeito relevante do processo de desenvolvimento mineiro, qualquer laivo de ilusão tecnocrática. O ponto de partida do que se entende por "desenvolvimento" é a sua compreensão como processo histórico, como processo marcado por contradições, por interesses conflitantes. Nesse sentido, não há propósito em atribuir ao BDMG, ou a qualquer órgão ou instância isoladamente, protagonismo em processo que é, sobretudo, coletivo, histórico-estrutural. Para dizer de outro modo: o desenvolvimento econômico e social de uma região ocorrerá na vigência de transformações estruturais que distribuam renda, riqueza e habilitações para o conjunto da sociedade, de modo a lhe permitir apropriar-se das novas tecnologias. Trata-se, como se vê, de processo político-social de grande envergadura, conduzido por forças so- 
ciais comprometidas com os valores da inclusão social, da democracia, da solidariedade e da sustentabilidade. A construção das identidades coletivas a partir das quais haverá a mobilização social passa pela elaboração de um "projeto", de uma "plataforma" abrangente que, fundada em estudos e pesquisas, seja capaz de mobilizar, de sustentar demandas, de estimular a luta social, de construir instituições e ações políticas concretas.

É uma conquista do pensamento crítico, a partir de nomes como Celso Furtado, ter superado a noção que fez sinônimos crescimento e desenvolvimento. Sabe-se, hoje, que o processo de desenvolvimento efetivo, propriamente dito, significa mais que crescimento, sobretudo, implicando transformações estruturais baseadas na distribuição da renda, da riqueza, do poder e do conhecimento.

Em 1966, o governo de Minas Gerais, mediante convênio, buscou implementar uma reforma visando à modernização da administração pública estadual. Entre os objetivos da reforma estavam: a melhoria dos padrões de eficiência dos serviços públicos; o estabelecimento das condições necessárias à promoção social e cultural do servidor público; a adição de processos adequados de organização e métodos simplificados e racionais de trabalho; a análise dos fatos administrativos e suas implicações econômicas e sociais, de modo a permitir, com fundamento em dados da pesquisa, de documentação e estatística, a elaboração de planos e tomada de decisões; entre outros (Mendanha, 2006, p. 19).

Como principal resultado do convênio foi instituída, pela lei no 4691, de 19/12/1967, o Centro de Processamento de Dados (Cepro). A administração do Cepro era exercida pelo Escritório Técnico de Racionalização Administrativa, Etra, executor do convênio Estado/UFMG (Mendanha, 2006, p. 23). Em 22 de novembro de 1968, o Etra foi transformado em Fundação, com os seguintes objetivos: realizar estudos, pesquisas, divulgação e, mediante ajuste, a aplicação dos princípios e métodos de organização racional do trabalho; planejar e assistir a implantação da reforma administrativa; executar o serviço de processamento de dados e tratamento de informações por sistema de mecanização de qualquer natureza; prestar serviços a qualquer entidade pública ou particular, conferindo prioridade aos serviços ajustados com órgãos da administração pública estadual (Mendanha, 2006, p. 25). Em 12 de outubro de 1972, por meio da Lei no 6003, a Fundação Etra foi transformada em Companhia de Processamento de Dados de Minas Gerais, Prodemge, que passou a vincular-se à secretaria de Estado do 
Planejamento e Coordenação Geral, em 22 de abril de 1975, por meio do decreto no 17.112 (Mendanha, 2006, p. 59).

O Etra, juntamente com o Conselho Estadual de Desenvolvimento e o BDMG, constituiu-se em elementos decisivos da constituição do sistema de planejamento atualizado em Minas Gerais. Foram o Etra, o BDMG e o Conselho Estadual de Desenvolvimento que encaminharam à Assembleia Legislativa projeto de lei para criar a Fundação João Pinheiro. Diz Antônio Octávio Cintra: "Em meados de 1969, foi enviado à Assembleia Legislativa do Estado projeto de lei que 'autoriza a instituição de Fundação destinada à pesquisa aplicada nos campos da economia, administração e da tecnologia básica e social."' (Cintra, 1979, p. 9). A criação da FJP foi o resultado concreto de estudo realizado pelo BDMG, Análise do Setor Público em Minas Gerais. A FJP foi instituída mediante a Lei no 5349, de 12 de setembro de 1969, com as seguintes áreas de atuação:

I. planejamento do desenvolvimento estadual, envolvendo estudo, pesquisa e programação econômico-social, inclusive estudo de oportunidade de investimento;

II. estudo de pesquisa, divulgação e aplicação de métodos e técnicas de organização racional do trabalho e processamento de dados por sistemas mecânicos, eletromecânicos e eletrônicos;

III. execução de serviços de geografia e estatística;

IV. execução de projetos de pesquisa e prestação de serviços no campo da tecnologia social básica;

$\mathrm{V}$. ensino, por meio de cursos afins com as atividades contidas nos itens anteriores. (Cintra, 1979, p. 6).

É certamente crucial para a adequada compreensão da história do planejamento em Minas Gerais que não se esqueça que os principais nomes da criação da Fundação João Pinheiro, foram dois dos mais importantes integrantes do BDMG: Fernando Antônio Roquette Reis e Hindemburgo Pereira Diniz, e que a motivação por essa iniciativa tinha uma dupla explicação: 1) a necessidade do BDMG se concentrar nas atividades precípuas de um banco de desenvolvimento; 2) a crescente complexidade das tarefas de planejamento decorrentes da expansão e complexificação da realidade contemporânea e seus impactos sobre Minas Gerais. Sobre a criação da FJP, disse Ronaldo Costa Couto (2014): "Seria um centro de excelência de estudos e propostas de interesse da economia mineira, em substituição ao BDMG, que exercia essa função mais por necessidade que por vocação. 
Assim, a Fundação absorveu parte da equipe do banco, principalmente do Departamento de Estudos e Planejamento".

Hindemburgo, primeiro Presidente da FJP, disse "O banco já estava consolidado, bem capitalizado, operando para a expansão da indústria e da agropecuária do estado, mediante empréstimo a pequenas e médias empresas." (Couto, 2014, p.111-112).

Fernando Reis aponta outra razão para a criação da FJP. Ele entendia que os custos de manutenção do DEP eram crescentes e pressionavam a situação financeira do banco (Couto, 2014).

A atuação do BDMG no campo do planejamento não foi interrompida com a criação da FJP, em 1969, já que o Banco manteve ativa presença na elaboração do IPMDES, 1971-75, resultado do convênio entre o Banco e o ILPES, e que vigorou até o final dos anos 1970. O IPMDES, transformado na Lei no 5852, de 14/12/1971, sob vários aspectos, foi a síntese da experiência do moderno planejamento econômico de Minas Gerais, iniciado em 1962, com a criação do BDMG. O protagonismo do BDMG nesse processo está perfeitamente explicitado entre os objetivos centrais do IPMDES. Entre as políticas de desenvolvimento regional propostas, o BDMG tem papel importante, diretamente, como fonte de financiamento, e indiretamente, na medida em que se atribuiu responsabilidade estratégica ao Indi, Instituto de Desenvolvimento Industrial, órgão criado por convênio entre a Cemig e o BDMG, e a CDI, Companhia de Distritos Industriais. Veja-se o texto:

descentralização das atividades industriais, através de incentivos fiscais, creditícios e infraestruturais. Para isto entraria em uma o BDMG com os financiamentos e projetos, a Secretaria da Fazenda e os municípios com a promoção de facilidades e isenções fiscais, o Instituto e Desenvolvimento Industrial (Indi) faria estudos de oportunidades industriais, e a Companhia de Distritos Industriais (CDI) ofereceria a infraestrutura em forma de Distritos Industrias (...) (Siqueira, 2001, p. 93-94).

Situado no limiar do chamado "milagre" econômico brasileiro, o IPMDES ainda foi vazado pela perspectiva que tinha marcado o desenvolvimento reformista, base das concepções do DEP, e do ILPES, que vão subsidiar o Gabinete de Planejamento e Coordenação (GPC, dentro do Conselho Estadual de Desenvolvimento, CED), chefiado por Fernando Antônio Roquette Reis, na elaboração do IPMDES. Clélio Campolina Diniz, analista qualificado da questão, porque também sujeito do processo, mostrou que a esta altura, final dos anos 1960, as novas tendências, representadas pelo 
"milagre", a opção pelo grande capital internacional, por uma concepção de desenvolvimento, que o identificava a crescimento econômico, sem maior preocupação com as desigualdades sociais, se instalaram no aparato do planejamento de Minas Gerais. Diz ele:

É necessário mencionar as divergências ideológicas e politicas entre os grupos de administração pública mineira. Após realizar o Diagnóstico da Economia Minei$\mathrm{ra}$, houve como um racha de orientações. Um grupo estava mais preocupado com uma orientação mais global para a solução dos problemas mineiros, incluindo não só os aspectos econômicos propriamente ditos, mas também os problemas sociais, de emprego, habitação, saúde, educação, etc., incluindo a ideia de desconcentração espacial da economia, e especialmente para evitar a concentração em Belo Horizonte. O outro preocupava-se apenas com a promoção da expansão econômica, especialmente da industrialização. Nas condições políticas brasileiras, torna-se claro que o apoio seria apenas para a orientação da expansão econômica a qualquer custo. O representante típico desta corrente foi o Indi, seguido pelo $B D M G$ e pela CDI, que, no seu afã de industrializar o Estado a qualquer custo, desenvolveu sua estratégia de apoio irrestrito ao capital estrangeiro e de concentração em torno de Belo Horizonte. (Diniz, 1981, p. 156-159).

O grupo perdedor nesta disputa foi o liderado pelo Gabinete de Planejamento e Coordenação, chefiado por Fernando Reis, que para Clélio Campolina Diniz havia sido derrotado, primeiramente, por ter "visão iluminista" de reformas sociais por meio do Planejamento, e, segundo, pelo desinteresse do sistema em objetivar soluções aos problemas levantados (Diniz, 1981, p. 159).

De todo modo, o BDMG continuou atuando em áreas sensíveis da administração pública estadual, como se deu no caso do convênio entre a Secretaria da Fazenda e o BDMG, com a interveniência do ILPES, na reforma da estrutura fazendária de Minas Gerais:

\footnotetext{
Entre outras decisões, a reforma fazendária promoveu a reestruturação interna da própria secretaria. Criou um sistema de caixa único. Centralizou a arrecadação através de rede bancária, despersonalizando o sistema de arrecadação e aplicação de recursos. Centralizou e controlou o orçamento. Centralizou a dívida pública e a receita de empréstimos. Controlou o sistema financeiro público estadual, subordinando todas as instituições financeiras aos subsistemas Banco de Crédito Real, Banco do Estado de Minas Gerais e Caixa Econômica Estadual e ao Controle destes através de um Conselho de Politica Financeira dentro da Secretaria da Fazenda (Diniz, 1981, p. 161-162).
}

Também significativas foram as ações do Banco voltadas para o chamado "polígono das secas". Em 1967, o DEP, realizou um amplo estudo sobre a região - "Área Mineira do Polígono das Secas: Situação e Problemas" - que vão deslanchar iniciativas substantivas para o desenvolvimento da região, como a realização do I Encontro de Investidores da Área Mineira do Polígono das Secas; a criação do Fundo de Financiamento de Estudos 
e Projetos para a Área Mineira do Polígono das Secas, Finepol; e a Ceaps, Carteira Especial de Aplicações na Área Mineira do Polígono das Secas (Diniz, 1981, p. 164).

\section{O BDMG e a criação do Cedeplar}

Outra iniciativa relevante do BDMG, com importantes impactos positivos sobre a compreensão da realidade mineira, sobre a formação de recursos humanos e na elaboração de propostas e políticas para o desenvolvimento regional e nacional, foi a criação do Cedeplar, em 1967, que inicialmente se chamou Ideplar. Fernando Correia Dias, em texto publicado em 1969, viu bem a questão e seus significados, disse ele:

\section{Ainda no âmbito dos problemas da economia regional, deveria ser realizado maior entrosamento entre a UFMG, o BDMG e o Conselho de Desenvolvimen- to, para efeito de estudos setoriais e regionais. Em fase de organização, encontra- -se o Instituto de Estudos e Planejamento Regional (Ideplar), que funcionará na Faculdade de Ciências Econômicas da UFMG, cuja implantação resulta de acordo entre a Universidade, o BNDE e a Cepal. (Dias, 1969, p. 134).}

A implantação da pós-graduação em Economia no Brasil é processo do início dos anos 1960, com a criação, em 1961, do CAE, Curso de Aperfeiçoamento de Economistas, da Fundação Getúlio Vargas do Rio de Janeiro, a que vai se seguir a criação, em 1965, do Instituto de Pesquisas Econômicas da USP.

Não se ignora que a implantação da pós-graduação em Economia no Brasil esteve longe de ser consensual ou pacífica, na medida mesmo que tanto suas motivações quanto seus sujeitos, referências teóricas e metodológicas, refletiam interesses e perspectivas político-ideológicas distintas, num momento de particular agudização da luta política. É neste contexto, refletindo os projetos em disputa, que se deu a discussão sobre a criação de um sistema de pós-graduação em economia no Brasil. Não há propósito, neste trabalho, de analisar em profundidade este processo. De todo modo, é o caso de situar a questão na medida em que ela é inescapável para a boa compreensão da história do Cedeplar ${ }^{1}$. Do ponto de vista da história do Cedeplar, trata-se de reconhecer o caráter heterodoxo de seu projeto acadêmico naquele momento. Se, de um lado, o Cedeplar buscou

1 Para maior detalhamento da questão, ver: Eckerman, 1989 e Szmrecsányi, 2001. 
atualização teórica, pela apropriação do básico e instrumental da teoria econômica dominante, de corte neoclássico; de outro lado o Centro, por suas origens fortemente lastreadas numa instituição, a Face/UFMG, que tinha uma longa história de colaboração e compartilhamento com o pensamento econômico cepalino e desenvolvimentista, e até mesmo pelo objeto privilegiado de seus estudos - o desenvolvimento e o planejamento regional - acabou por manter posição equilibrada entre a emergente hegemonia neoclássica e a matriz estrutural-desenvolvimentista. Mais tarde, nos anos 1970, esta opção foi tomada como estratégica pela instituição, pela efetiva valorização e compromisso com uma perspectiva pluralista de ensino e pesquisa em economia, que é a única, de fato, legitimamente compatível com o sentido mesmo da vida universitária.

Os primeiros anos do Cedeplar foram marcados pela autoformação de sua equipe, num processo que tem muito de autodidatismo. Foram anos de intensa dedicação à apropriação da teoria econômica regional e dos métodos de análise regional, proposta de uma equipe jovem e que não tinha tido preparo específico no tratamento dessas problemáticas. Para a efetiva capacitação da equipe em economia regional, foram desenvolvidas três iniciativas básicas: 1) a organização de programa de estudos e seminários internos; 2) colaboração de especialistas estrangeiros; 3) a ida de membros da equipe para o exterior para realizarem estudos de pós-graduação. Todas as três iniciativas foram intensamente praticadas durante os anos iniciais do Cedeplar. Um exemplo disso é que dos oito membros da equipe do Cedeplar em 1968, todos eles realizaram estudos de pós-graduação no exterior, sendo cinco nos Estados Unidos, dois na Holanda e um na Inglaterra. Ao mesmo tempo, o Cedeplar buscou trazer especialistas em economia regional para temporadas de curta e média duração na Instituição, bem como manteve intenso programa de conferências e seminários com nomes importantes das ciências sociais do Brasil e do exterior. Entre os especialistas estrangeiros em economia regional, que participaram dos primeiros tempos do Cedeplar, estão os professores Josef Hilhorst, do Institute of Social Studies, de Haia, e Arthur Silvers, do Resource for Future, Inc., de Washington. Entre os que visitaram o Cedeplar para contatos e para ministrar conferências, citem-se: Nicolas Georgescu Roegen, da Universidade Vanderbilt; Martin T. Katzman, da Universidade de Vanderbilt; A. Harberger, da Universidade de Chicago; Henri Guitton, da Universidade de Paris; Sterling Brubaker, da Resource for the Future, Inc.; Hans G. T. Van Raay, 
do Institute of Social Studies, de Haia; Kwamina B. Dickson, da Universidade de Ghana; Walter B. Stöhr e Harold Wood, da McMaster University, de Ontário, Canadá; John Philip Dickinson, da Universidade de Liverpool; entre outros nomes.

Os primeiros tempos do Cedeplar, entre 1968 e 1974, são marcados pela busca da apropriação de instrumentos teóricos e metodológicos no campo da economia regional. Essa busca de elementos teóricos e metodológicos se fez sem perder de vista, seja as grandes questões da realidade socioeconômica brasileira, seja a valorização de perspectiva pluralista, que recusou dogmatismos e autoatribuídos monopólios da verdade e da cientificidade.

Neste sentido, diga-se que o Cedeplar, tendo sido criado num momento em que se buscava circunscrever a pós-graduação em Economia no Brasil aos marcos da perspectiva dominante na academia anglo-saxã, tendo recebido recursos e apoio financeiro e recursos humanos de fundações e organismos sintonizados com o mainstream, não se deixou aprisionar, reafirmando, com isso, o sentido mesmo do melhor da instituição universitária, e da história da Face/UFMG.

$\mathrm{Na}$ prática, isso se traduziu na reiteração de um ambiente acadêmico em que a economia regional, neoclássica, era considerada ao mesmo tempo que outras perspectivas teóricas e metodológicas, outras disciplinas como a geografia, a demografia, a sociologia, a história, bem como se estava atento ao debate sobre os grandes desafios da sociedade brasileira, tal como o protagonizado naqueles anos por nomes como Celso Furtado, Francisco de Oliveira, Paul Singer, Maria da Conceição Tavares.

Uma lista das publicações do Cedeplar nesse período, 1968-1974, reflete o que se disse aqui sobre o processo de apropriação das teorias e métodos de análise em Economia Regional, bem como a implantação da Demografia como campo de estudos do Centro, resultando, em 1974, na criação da área de Concentração em Demografia Econômica, no curso de mestrado em Economia. Os estudos demográficos vinham ocorrendo no Cedeplar, desde 1971, quando, mediante recursos da Fundação Ford, o Centro passou a contar com a valiosa presença do professor Thomas Merrick. No final de 1973, com a volta do professor José Alberto Magno de Carvalho de seu doutoramento em Demografia, na London School of Economics, o Cedeplar deu início à sua consolidação como um dos mais importantes centros de estudos demográficos do Brasil, com amplo reconhecimento internacional. 
Desde sua criação, o Cedeplar tem experimentado importantes modificações motivadas tanto por razões internas (saída de parte da equipe ligada ao BDMG), quanto por variados influxos externos: a Reforma Universitária de 1968, que modificou significativamente o funcionamento da Universidade; as variadas consequências sobre a vida universitária decorrentes do recrudescimento repressivo com o AI-5, o expressivo crescimento da economia brasileira naquele período.

O fato é que a implantação da pós-graduação em economia no Brasil coincidiu com o período de rápido crescimento da economia brasileira, chamado de "milagre" econômico brasileiro. Tal coincidência resultou na atribuição de uma relação espúria de causalidade. Com efeito, o fato de que nomes importantes da equipe econômica dos primeiros governos da ditadura tivessem ligações com centros de pós-graduação em economia do Rio de Janeiro e de São Paulo, no momento em que a economia crescia e aparentemente era impulsionada pelas "ideias econômicas" dessas instituições, acabaram por estabelecer uma quase identidade entre "pensamento econômico neoclássico e boa política econômica", isto é, política econômica de país com crescimento econômico expressivo.

Para todos os efeitos, a economia brasileira do "milagre" teria consagrado a hegemonia do "pensamento econômico neoclássico", quando de fato, o "pensamento econômico neoclássico" dominante a partir da implantação da pós-graduação em economia no Brasil foi o que consagrou a ordem econômica implantada pós-1964, e sua completa adesão ao grande capital, à concentração da renda e da riqueza, sua conivência com a opressão política. Com efeito, o crescimento econômico daquele período, os determinantes do chamado "milagre econômico brasileiro", não resultaram da aplicação de qualquer sorte de ortodoxa "caixa de ferramentas" neoclássica. Trata-se aqui de reconhecer que o êxito da política econômica da ditadura militar, durante certo tempo, sobretudo entre 1970 e 1973, tem vários e complexos determinantes, como tem várias e problemáticas consequências, como o aprofundamento da concentração da renda e da riqueza e o aumento da fragilidade externa da economia brasileira.

Tudo isso considerado, a situação do Cedeplar, neste contexto, foi equilibrada seja porque não adotou, em toda a linha, a tradição neoclássica, cultivando mesmo certos elementos de teorias críticas, sem perder de vista os aspectos estruturais histórico-sociais dos processos econômicos. 


\section{A FACE/UFMG: modernização e pensamento crítico}

A interação entre o Cedeplar e o BDMG, que tem sido permanente, remete à origem comum das duas instituições: a Faculdade de Ciências Econômicas da UFMG. Sob mais de um aspecto, a Faculdade é uma das matrizes importantes da modernização econômica e administrativa de Minas Gerais, seja como formadora de recursos humanos, seja como centro atualizado de ensino e pesquisa em Ciências Sociais aplicadas. Alguns dos nomes mais importantes da geração de pioneiros quadros dirigentes da alta administração pública estadual mineira foram professores da Face, como José de Magalhães Pinto, que foi Secretário da Fazenda do Governo Milton Campos, e Lucas Lopes, que foi Secretário de Agricultura do Governo Benedito Valadares. Antes de ocupar a Secretaria da Fazenda, Magalhães Pinto fora Presidente da Associação Comercial de Minas Gerais, e um dos fundadores do Banco Nacional de Minas Gerais. Lucas Lopes, professor de Geografia Econômica da Face/UFMG, depois de deixar a Secretaria de Agricultura, coordenou a elaboração do Plano de Eletrificação de Minas Gerais, tendo sido o primeiro Presidente da Cemig, ocupando, ainda, cargos no BNDE, tendo sido, também, Ministro da Fazenda durante o governo Juscelino.

A Faculdade de Ciências Econômicas da UFMG teve decisiva participação na implantação, em Minas Gerais, de uma sólida tradição em planejamento do desenvolvimento econômico e social, pelos significativos avanços alcançados com seu projeto acadêmico, sob mais de um aspecto inovador, seja pela profissionalização de seu quadro docente; pela introdução do tempo integral para seus alunos da graduação; pela constituição de centro de ensino e pesquisa em ciências sociais aplicadas, com cursos de graduação em ciências econômicas, ciências contábeis, ciências atuariais, administração pública, sociologia e política e administração de empresas; seja pela introdução da prática permanente de pesquisa informada por metodologia atualizada; seja pela efetiva constituição de um ambiente de cooperação interdisciplinar; seja na consolidação da publicação dos resultados das pesquisas como atividades inerentes ao fazer da instituição; seja pela criação de um ambiente motivador de atuação política e cultural de seus docentes e discentes.

O golpe de 1964 teve forte incidência na vida da Faculdade. Visado como centro do pensamento crítico de esquerda, como centro de militância política antiditadura, a Faculdade continuou, apesar da repressão, a de- 
sempenhar papel significativo de resistência e ação política. Destacou-se, neste momento, a intensificação da mobilização de atividades culturais, mediante a ressignificação de instituições, espaços, formas de expressão e comunicação, os quais ganharam uma extraordinária potência crítico-criativa, transformando-se, de fato, em espaços de resistência e mobilização, como o Cine Clube Face, a organização de espetáculos musicais e teatrais, a publicação de jornais, revistas, livros, a tradução e a veiculação de textos críticos.

Fez parte desse momento, a construção de uma agenda alternativa de referências, autores, questões que contestavam o discurso oficial, o ufanismo do Brasil Grande Potência, do "milagre" brasileiro. Ao triunfalismo da propaganda oficial, setores importantes do pensamento crítico brasileiro, contrapuseram a constatação da concentração da renda e da riqueza no Brasil, entre 1960/70; denunciaram as mazelas estruturais das grandes cidades, o outro lado do "milagre" expresso nas iníquas condições de vida dos trabalhadores do campo e da cidade.

A hegemonia desenvolvimentista, que marcou o Brasil nos anos 1950/60, também marcou a Faculdade de Ciências Econômicas da UFMG. Tanto ali, quanto no conjunto do país, falar de hegemonia é reconhecer a existência de forças heterogêneas em disputa. Assim, o golpe de 1964 e a inflexão que ele determinou sobre os sujeitos e destinatários do desenvolvimento, o protagonismo que passaram a ter os interesses do grande capital nacional e estrangeiros impactaram a vida nacional em vários e decisivos aspectos. No que interessa à discussão que se está fazendo aqui, trata-se de reconhecer que as novas forças hegemônicas na sociedade brasileira promoveram uma significativa alteração no ensino e na pesquisa em economia no país, com a efetiva imposição de uma majoritária adesão ao pensamento econômico neoclássico, na mesma medida em que se secundarizava, se desqualificava todas as correntes que não se perfilhavam ao paradigma neoclássico. Tal operação não se limitou à modificação curricular, envolvendo tanto interdições quanto premiações por parte das agências de financiamento de pesquisa, de publicações, de redes de apoio, de construção de pretensos consensos, de arbitrárias decisões do poder público sancionadoras de "grupos de excelência" e "agendas relevantes".

Com efeito, a Faculdade de Ciências Econômicas da UFMG sofreu duplamente os efeitos da nova hegemonia modernizante autoritária que se instalou no Brasil em 1964. Diretamente, pela repressão, pela censura, 
pela aposentadoria repressiva, pela prisão e afastamento de professores e estudantes, pela extinção do curso de sociologia e política no âmbito da Faculdade; indiretamente, pela interdição dos temas, dos autores, das teorias, das perspectivas que a Faculdade, hegemonicamente, elegeu no contexto da época desenvolvimentista. Confrontada com esta nova realidade, a Faculdade reagiu, buscou resistir. A criação do Cedeplar é parte desta tentativa.

\section{BDMG e Cedeplar: espaços do desenvolvimentismo mineiro}

A criação do BDMG foi o resultado de um complexo encadeamento de circunstâncias a que não faltaram certos aspectos desconcertantes. Afinal, o Banco foi criado de maneira queo governador do Estado tem o poder de proferir vetos, os quais reconfiguraram o projeto original aprovado pela Assembleia Legislativa. Ideia inicialmente lançada no primeiro ano do governo Juscelino Kubitschek, em Minas Gerais, em 1951, antes mesmo da criação do BNDE, o BDMG acabou sendo criado no governo comandado pela UDN, partido tido por liberal em matéria política e econômica. Esse aparente paradoxo já tinha se verificado antes na pioneira manifestação de planejamento econômico no Brasil com o Plano de Recuperação Econômica e Fomento da Produção, de 1947, do governo udenista de Milton Campos.

A explicação do suposto paradoxo está na longa hegemonia do desenvolvimentismo no Brasil, o desenvolvimento no Brasil experimentou fases e ênfases diferenciadas. O golpe de 1964 e a ditadura civil-militar, que se implantou então, não significaram abandono do desenvolvimentismo, com duas exceções: entre 1964-67, pela ênfase ortodoxa no ajuste econômico, que foi tentado; entre 1979-85, pela agudização da crise econômica, crise do Balanço de Pagamentos, crise inflacionária, que impuseram à economia brasileira uma longa recessão e uma completa fixação da política econômica em administrar, sem sucesso, o dia a dia de uma crise sem fim.

A criação do BDMG deu-se no âmbito da reversão do ciclo expansivo comandado pelo Plano de Metas. No início dos anos 1960, foram explicitadas algumas contradições que tinham acompanhado o ciclo expansivo, 1956-60, sob a forma da aceleração inflacionária e do estrangulamento cambial. Contra esse quadro já de crise aberta, lançou-se, inicialmente, 
o receituário ortodoxo do governo Jânio Quadros, que fracassou. A experiência parlamentarista que se seguiu à renúncia de Jânio Quadros foi igualmente incapaz de superar a crise. Na iminência de recuperar os plenos poderes presidenciais, João Goulart lançou, em dezembro de 1962, o Plano Trienal, que não teve tempo de produzir qualquer resultado positivo.

É nesse contexto que foi criado o BDMG, instituição típica de uma época, de um ethos, marcado pela ideologia do desenvolvimentismo, o qual englobou o poder público, o ensino, a pesquisa, os meios de comunicação, as forças políticas e sociais do país. No caso do BDMG, suas referências constitutivas fundaram-se na longa tradição da presença do Estado em atividades econômicas que se traduziu numa expressiva rede de instituições de pesquisa e planejamento. Entre essas instituições tem destaque a Face/ UFMG. Não por acaso, os dois primeiros presidentes do BDMG, Obregon de Carvalho e Paulo Camilo de Oliveira Penna, foram professores da Face. O primeiro, Professor de Valor e Formação de Preços, disciplina que hoje em dia talvez se chamasse "Teoria microeconômica". Obregon de Carvalho é autor de dois artigos publicados na Revista da Face, um em 1952 - "Da liberdade individual e seu conflito com o interesse público"; e outro em 1954 - "A procura dos bens de consumo", em que dá mostras de conhecimento atualizado não só da bibliografia francesa que dominava os cursos de economia de então, como de domínio da moderna teoria econômica anglo-saxã, tanto de origem neoclássica (Marshall, Hicks) e dos institucionalistas (Veblen), quanto do pensamento de Keynes (Carvalho, 1954). Paulo Camilo de Oliveira Penna foi professor de Administração Pública da Faculdade de Ciências Econômicas da UFMG e realizou estudos de pós-graduação na França, tendo então tomado contato com a importante tradição francesa de planejamento indicativo, a qual marcou a vida política e econômica daquele país depois da II Guerra Mundial.

É com Paulo Camilo de Oliveira Penna que o BDMG consolidou uma de suas principais características, que o distinguem no cenário das instituições bancárias, mesmo entre aquelas voltadas para o financiamento do desenvolvimento econômico, que é a centralidade que a busca da compreensão crítica da realidade regional, nacional e mundial tem em sua atuação. Sobretudo a partir da escolha de Fernando Antônio Roquette Reis para a chefia do Departamento de Estudos e Projetos, o BDMG vai se tornar um efetivo centro de produção de conhecimento e formulação estratégica do processo de desenvolvimento econômico de Minas Gerais. Quando, entre 1965- 
1966, problemas internos ameaçaram o programa de estudos e projetos do Banco, Fernando Reis, juntamente com Álvaro Santiago e Élcio Costa Couto, busca dar continuidade aos projetos e pesquisas mediante a criação de um órgão junto à Faculdade de Ciências Econômicas da UFMG, que veio a ser o Cedeplar. Não só nesse primeiro momento de criação houve ligação entre o BDMG e o Cedeplar. Com efeito, mesmo depois da criação da Fundação João Pinheiro, que absorveu muitas das funções do Banco, no que diz respeito à pesquisa e planejamento, manteve-se a ligação orgânica entre o BDMG e o Cedeplar. Trata-se, mais do que apontar os vários campos em que tem se dado a cooperação entre o BDMG e o Cedeplar, mas de reconhecer uma base comum de referências, uma identidade institucional básica, resultante da circulação permanente de pessoas, da circulação permanente de ideias e perspectivas teóricas e metodológicas. É exemplar disso a participação de membros do Cedeplar nas três rodadas de elaboração do "Diagnóstico da Economia Mineira", em 1969, 1989 e 2002.

Em sentido complementar, seria igualmente expressiva a lista dos técnicos do BDMG oriundos da Faculdade de Ciências Econômicas. O Diagnóstico da Economia Mineira, editado em 1969, tem sido avaliado, às vezes, com rigor excessivo, algo anacrônico. Afinal, exigir daquele documento, resultado do trabalho de uma equipe ainda em formação, maior clarividência teórica e metodológica é ignorar seus grandes méritos. Quando comparado com iniciativas similares no Brasil, é minimizar sua potência como instrumento político, de mobilização de vontades, de denúncia de históricas mazelas sociais. O Diagnóstico é, sem dúvida, um dos documentos mais expressivos nascidos do poder público mineiro, com importância equivalente à do Plano de Recuperação de 1947. Sua elaboração deveu-se em grande medida a Fernando Reis, seu inspirador e coordenador. De sua elaboração participaram outros membros do BDMG, com vinculação com a Faculdade de Ciências Econômicas da UFMG, citem-se alguns: Álvaro Fortes Santiago, Antonio Luiz Portugal Moura, Clélio Campolina Diniz, Élcio Costa Couto, Gelmar Benedito Costa, Marneu Ferreira Starling, Teodoro Alves Lamounier, Fernando Correia Dias, José Armando de Souza, José Murilo de Carvalho. A esses se somem outros, que sendo da Face/ UFMG, também pertenciam ao Cedeplar: José Birchal Wanderley, Paulo Roberto Haddad, José Alberto Magno de Carvalho, Walter Fouad Couri.

Na segunda rodada do "diagnóstico", de 1989, chamado Economia Mineira. 1989. Diagnóstico e Perspectiva, também expressiva foi a participa- 
ção da Faculdade e do Cedeplar. Naquele momento, ocupavam cargos de superintendente no BDMG dois ex-alunos da Face, Mauro Santos Ferreira, economista formado pela Faculdade, e Paulo Eduardo Rocha Brant, que foi aluno do Cedeplar, professor da Faculdade e supervisor geral do estudo. A coordenação do trabalho foi exercida por ex-aluno da Faculdade, Iran Almeida Pordeus. Entre os membros da equipe citem-se alguns com vinculação com a Faculdade ou com o Cedeplar: Ana Flávia Machado, Carlos Francisco Gomes, Francisco Gaetani, Henrique Tostes Reis, Laura Michelis Mendonça, Marilena Chaves, Matheus Cotta de Carvalho, Roberto Mário Gonçalves Soares Filho.

Em 2002, a terceira rodada do "diagnóstico" chamou-se Minas Gerais do século XXI, foi o mais abrangente dos estudos, com 10 volumes. A coordenação geral coube a Tadeu Barreto Guimarães, ex-aluno do Cedeplar, sendo a coordenação técnica exercida por Marilene Chaves, economista formada pela Faculdade de Ciências Econômicas da UFMG. Entre os membros da equipe técnica do Departamento de Planejamento, Programas e Estudos Econômicos do BDMG contavam-se, entre outros nomes ligados à Faculdade, Bernardo Tavares de Almeida, Juliana Rodrigues de Paula Chiari e Gislaine Ângela do Prado.

Não é possível, pela extensão que teria a lista, reportar todos os técnicos do BDMG, atuais e do passado, formados pela Face, em número menor, mas não muito, seria a lista daqueles que tendo passado pelo Cedeplar atuaram no BDMG. Registre-se que essa dupla vinculação tem considerável impacto sobre o que tais instituições são. Afinal, há como uma fecundação recíproca em que conceitos, teorias e metodologias são apreendidas e mobilizadas para enfrentar questões e problemas práticos, as tarefas do planejamento do desenvolvimento econômico, que, em sentido inverso interpelam o fazer acadêmico compelindo-o à atualização, à aproximação das questões concretas postas pela realidade econômico-político-social. Com efeito, esses efeitos de fecundação recíproca são particularmente evidentes quando se consideram os dirigentes dessas instituições. Com interrupções, motivados por questões político-partidárias, é possível dizer que o BDMG tem tido dirigentes com fortes vínculos com a Faculdade ou com o Cedeplar.

Entre os que ocuparam a Presidência do Banco, oito tiveram ligação com a Face e ou Cedeplar, a saber: Obregon de Carvalho, Paulo Camilo de Oliveira Penna, Marco Túlio Felício da Silva, os quais foram professores 
da Faculdade; João Batista de Abreu e Matheus Costa de Carvalho são economistas formados pela Face; Ronaldo Costa Couto, Paulo de Tarso de Almeida Paiva, Marco Aurélio Crocco foramprofessores da Faculdade e do Cedeplar. Entre outros nomes que participaram do Conselho de Administração e têm ou tiveram vinculação com a Faculdade estão João Heraldo Lima, Paulo Roberto Haddad, Ronaldo Lamounier Locatelli, José Afonso Bicalho Beltrão da Silva.

Esta interação entre BDMG e Cedeplar não significa unidade de ação, identidade teórica, política ou programática, que as duas instituições têm objetivos, métodos de ação, públicos-alvo e missões específicas. Nesse sentido, o Cedeplar, tem buscado desenvolver seu maior patrimônio, que é o respeito à pluralidade política, teórica e ideológica, sem abdicar dos compromissos da universidade pública, laica e crítica com a plena emancipação humana. O Cedeplar tem buscado ser um espaço de resistência, imune aos modismos e aos autopropalados monopólios da racionalidade e do saber, de defesa de perspectivas que se recusam a aceitar a ditadura do pensamento único. Quanto ao BDMG, não seria elogio despropositado dizer que representa a uma das grandes matrizes da moderna cultura do planejamento e do desenvolvimento de Minas Gerais.

\section{Referências}

CARVALHO, Obregon. A Procura de bens de consumo. Revista da Faculdade de Ciências Econômicas, da Universidade de Minas Gerais, Ano III, n. 5, janeiro-junho, 1954.

CINTRA, Antônio Octávio. FUNDAÇÃO João Pinheiro. Notícia histórica. Áreas de atuação. Trabalhos Realizados. Belo Horizonte: FJP, 1979.

COUTO, Ronaldo Costa. Fernando Coragem Reis. Sonho e Glória. Amor e Dor. Brasília, 2014.

DIAS, Fernando Correia. Estado e Desenvolvimento em Minas Gerais. Revista Brasileira de Estudos Políticos. Belo Horizonte, n. 25 e 71, julho, 1968, janeiro, 1965.

DINIZ, Clélio Campolina. Estado e capital estrangeiro na industrialização mineira. Belo Horizonte: EUFMG, 1981.

ECKERMAN, Raul. A comunidade de economistas do Brasil: dos anos 50 aos dias de hoje. Revista Brasileira de Economia, vol. 43, n. 8, abril/junho, 1989.

FURTADO, Celso. O desenvolvimento do ponto de vista interdisciplinar. Ensaios de Opinião. v. 10. Rio de Janeiro: Paz e Terra, 1979.

MEDEIROS, Jarbas. Politica e administração para o desenvolvimento econômico e social de Minas Gerais. Belo Horizonte, 1966. 
MENDANHA, Domingos de Carvalho. A Prodemge e sua História (1966-1995). Belo Horizonte: Prodemge, 2006.

REIS, Fernando Antônio Roquete. Elementos para uma teoria do planejamento regional. Revista Brasileira de Ciências Sociais, Belo Horizonte, FACE/UFMG, vol. III, n. 1, março 1963.

REIS, Fernando Antônio Roquete. Prefácio. Cadernos BDMG, n. 1, Belo Horizonte: BDMG, 1968.

SIQUEIRA, Jack. Planejamento e Desenvolvimento em Minas. Belo Horizonte: Armazém de Ideias, 2001.

SZMRECSÁNYI, Tamás. (Org.). Dossiê Pensamento Econômico Contemporâneo. Revista Estudos Avançados, USP, vol. 15, n 41, janeiro/abril, 2001.

\section{Sobre o autor}

João Antonio de Paula - depaula@cedeplar.ufmg.br

Professor do Cedeplar/FACE/Universidade Federal de Minas Gerais.

\section{Sobre 0 artigo}

Recebido em 18 de abril de 2017. Aprovado em 17 de julho de 2017. 